\title{
Parametric Study of the Flow in the Horizontal Absorber Tube of the Parabolic Trough Collector
}

\author{
Tarek Mekhail \\ Dept. of Mech. Power Engineering \\ Faculty of Energy Engineering, Aswan University \\ Aswan, Egypt. \\ tmalak@aswu.edu.eg \\ Michael N. Mekhael \\ Dept. Electronics and Communications. \\ Faculty of Engineering, Benha University, Egypt \\ michael.gerges@feng.bu.edu.eg
}

\author{
Mohamed Fathy Cidek \\ Dept. of Mech. Power Engineering \\ Faculty of Energy Engineering, Aswan University \\ Aswan, Egypt. \\ mfsadik@yahoo.com \\ Imran Afgan \\ Senior Lecturer and Director MSc Thermal Power \& Fluids \\ Engineering, The University of Manchester \\ imran.afgan@manchester.ac.uk
}

\begin{abstract}
The inability of base fluid to carry sufficient amount of thermal energy to the storage system or power block has encouraged researchers to improve the performance of base fluid by adding particles suspended in the base fluid to improve thermal properties of resulting fluid (nanofluid). Besides, several options can be used for improving heat transfer associated with internal flow inside a solar receiver. This augmentation in convection heat transfer can be obtained by increasing the convection heat transfer coefficient and /or by increasing the convection surface area. Inducing swirl by twisted tape inside the receiver enhance convection heat transfer coefficient. In this paper an indoor test rig has been designed and manufactured for this purpose. A measuring technique has been implemented and executed for measuring all parameters regarding heat transfer and fluid flow to simulate the outdoor test rig of the parabolic trough absorbing tube. The measuring technique shows that the error is less than 1 percentage, In addition non uniform heat temperature distribution has been measured.
\end{abstract}

Keywords-Parabolic trough, absorbing tube, heat transfere

\section{INTRODUCTION}

The scarcity of available energy resources has been further aggravated by the ever-increasing of the world energy demand. In addition, current energy production from coal and oil is damaging to the environment and nonrenewable. It is widely known that the global warming became a very critical issue and it is harmful at the same times. Therefore, it is very necessary for researchers bear in mind how to tackle this concern. To solve this problem, a clean, renewable and sustainable source should be provided to reduce the amount of $\mathrm{CO}_{2}$ emissions. The solar thermal energy is one of the helpful solutions in terms of a reduction in usage the fossil fuels, decrease the level of the greenhouse-gas emissions and meet the requirements of humans. However, the surface of the earth is exposed to the sunlight, directly and indirectly, due to some deviations and reflections in the atmosphere, and then the photons which are comprised from the solar radiation are converted directly into electrical power either by using photovoltaic devices or Concentrating Solar Power (CSP) plants. The energy used in the CSP plants is called Direct Normal Irradiance (DNI) which can be described as the amount of received solar energy per unit area on the surface held normal to the rays of the sun. Recently, the (CSP) technology can be categorised into four main families depending on the method that be used to receive the sun's energy and they concentrate the sun's rays, these are; parabolic trough collectors (PTC), linear Fresnel reflectors, parabolic dishes and solar towers, as shown in Fig. 1

Jeter [1] published a paper presented that the non-uniform distribution of heat flux distribution where a semi-finite formulation had been derived and developed from the first integral of the concentrated flux density differential equations for the types of trough collectors. Two cases were selected to be examined using the resulting formula. The first case was a flat receiver tube at the focal plane within the PTCs; whereas, the second case which is a more realistic case was a round absorber tube within the PTCs. It was concluded that the resulting formula can be easily and quickly used to calculate the concentrated flux distribution needed for the optimal efficiency, heat transfer computations.

Dudley et al. [2] studied experimentally the effect of thermal losses on solar collector efficiency through the parabolic solar collector of Solar Electric Generating System (SEGS) plants. Two types of collectors were used with different coatings; black chrome and cermet using three different annuals; vacuumed, filled with air, and the glass cover was totally removed from the collector in the third case. They deduced that all these configurations had affected individually the performance of the solar collector. The best performance was recorded by the first case coating with cermet and a gradual decrease was noticed when changing to the black chrome coating and again a progressive degrade had been presented by implementing the second and third cases. The equations of the collector thermal performance and heat losses related to the operating temperature and incidence angle were derived for each single configuration.

It can be said that the authors above are pioneers in this field and the majority of authors came after them considered their work to compare with the numerical studies like Odeh et al. [3], Cheng et al. [4], Hachicha et al. [5], Sokhansefat et al. [6], and , Kaloudis et al. [7],

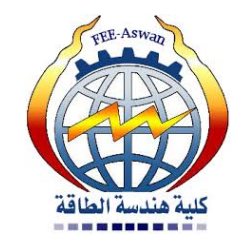




\section{PARABOliC TROUGH COLLECTOR}

The Parabolic Trough Collector (PTC) family is the most mature candidate and dominant technology used currently in both commercial and industrial solar thermal power scaleplants for a medium-temperature collector. The solar thermal power plant consists mainly from three blocks (sometimes two: without the solar storage) called; solar field, storage system and power block. The solar field can be described as a heat exchanger tool that transfers the received solar radiation into heat which in turn can be employed for generating power. The main purpose of the solar collector is to convert the absorbed incident solar radiation into thermal energy carried through the receiver by the heat transfer fluid (HTF). The HTF connects the solar field to power block carrying the heat from the solar collector to the steam generator or to the storage system.
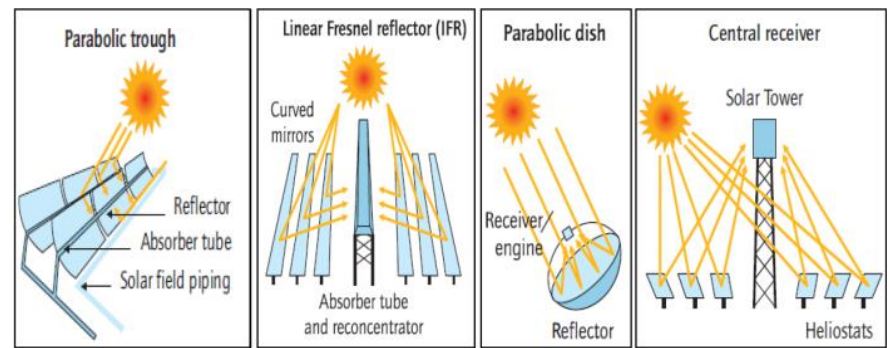

Fig. 1 The CSP families

The efficient design of PTC should have light structures as well as large efficiency. Basically, the PTC consists of several sheets made from reflective materials (using usually silvered acrylic). These sheets are bent to provide a parabola shape and all of them are placed in series in order to create long troughs. The troughs are connected to pedestals from both sides to support them from the earth. The parabolic trough has a focal line along in which the absorber is mounted.

The absorber tube is made generally from metal coated with the black colour to achieve larger solar absorbance as well as smaller thermal emittance and it is surrounded by a glass envelope covered with the anti-reflective coating in order to reduce the heat losses by convection. The space between the absorber and the glass envelope can be vacuumed (typically maintained at $0.013 \mathrm{~Pa}$ ) to further reduce the heat losses which in turn enhance the block's efficiency, (Barlev et al.) [8], all components of PTC are shown in Fig. 2 [9]

\section{Absorber tube}

This component (also called a heat collection element or receiver) is the most important element in the PTC system made typically from steel coated by multilayer cermet coating leading to provide very good optical properties, low thermal emissivity and large solar absorptivity. Its length is generally $4 \mathrm{~m}$ between the two support braces and might be extended to $150 \mathrm{~m}$. However, the outer diameters of the absorber and glass envelope are about $70 \mathrm{~mm}$ and $115 \mathrm{~mm}$ respectively.

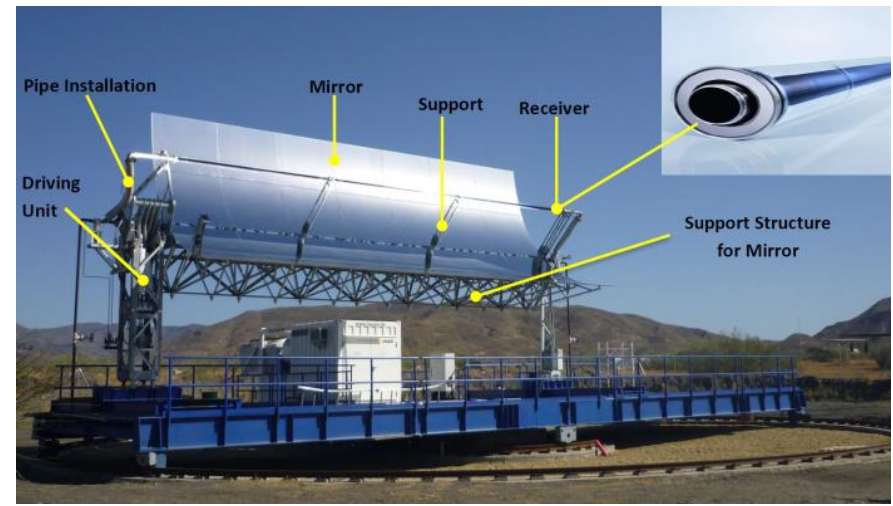

Fig. 2 The structure and elements of parabolic trough collector

\section{PTC reflector}

This element is also a very important device consists of mirrors and structures used to reflect solar energy to the receiver and it has a large specular reflectance (more than $88 \%$ ). It is usually made from low-iron float glass (approximately 4mm) and large solar transmittance is provided. Mirrors are usually silvered from the back and coated with some selective coatings because of their solar reflectance $(\mathrm{SR}=0.93)$ and durability are better if it is compared with the polished aluminium $(\mathrm{SR}=0.87)$ and; moreover, it is available. The installation, as well as the mounting of the structures, has a large effect on the overall performance of the plant (Kreith and Goswami [14]).

\section{Heat Transfer Fluid (HTF)}

The function of HTF is to carry and collect the thermal energy received from the receiver to the storage system or directly to the power block. However, selecting the appropriate HTF depends on major requirements in which the best choice of HTF should have large thermal stability, a wide range of liquid temperature, low vapour pressure, environmentally friendly, large thermal conductivity, large density, high heat capacity, low cost, low viscosity, small thermal expansion coefficient, large heat transfer coefficient, easy piping and no problem with wall materials, (Nahhas et al. [10]. Table 1 presents a comparison among some HTFs used in current plants. The usage of water would increase the cost of the plant since the high pressure would be produced inside the absorber pipe; therefore, in the current PTC designed for more than $200{ }^{\circ} \mathrm{C}$, thermal oils are usually employed. Besides that, an excellent stability has been shown by using Biphenyl-diphenyl-oxide (Therminol VP-1) and Dowtherm A in spite of those requirements of safety, flammable and environmental protection could be accepted with reasonable effort.

Table 1: Advantages and limitations of HTFs used in current CSP, (Nahhas et al.[10]).

\begin{tabular}{|c|l|l|l|}
\hline HTF type & $\begin{array}{l}\text { Provided } \\
\text { temp. }\left({ }^{\circ} \mathbf{C}\right)\end{array}$ & Advantages & Drawbacks \\
\hline Water & $\begin{array}{l}250(\text { at } \\
\mathrm{p}=0.4 \\
\mathrm{MPa})\end{array}$ & Very cheap & $\begin{array}{l}\text { Large Temp. } \\
\text { Leads to large } \\
\text { pressure and } \\
\text { cost. }\end{array}$ \\
\hline
\end{tabular}




\begin{tabular}{|l|l|l|l|}
\hline Synthetic oils & $13-400$ & Good performance & $\begin{array}{l}\text { Toxic, } \\
\text { Flammable } \\
\text { and highly } \\
\text { priced }\end{array}$ \\
\hline Molten salts & $230-600$ & $\begin{array}{l}\text { Large thermal } \\
\text { stability \& can be } \\
\text { used as storage } \\
\text { media as well. }\end{array}$ & $\begin{array}{l}\text { Solidification } \\
\text { at } \mathrm{T}=230^{\circ} \mathrm{C} \\
\text { and cause } \\
\text { Corrosion. }\end{array}$ \\
\hline Air & $>600$ & Very cheap & $\begin{array}{l}\text { Poor } \\
\text { performance. }\end{array}$ \\
\hline
\end{tabular}

\section{PROBLEM CONSIDERED AND TEST FACILITY}

Parabolic trough CSPs work on the principle of thermal energy extraction via reflection of sunlight onto receiver tubes. The working fluid then passes through a heat exchanger generating steam for power generation; any excess energy is stored into storage tanks. The non-uniform heating as sunlight reflected only on one side of tubes remains a big issue in heat transfer process.

An indoor test facility has been constructed so that it simulates the outdoor parabolic trough test facility as shown in Fig. 2. It consists of a heating coil of $10 \mathrm{~kW}$ inside a container of dimensions $1 * 0.15^{*} 0.15 \mathrm{~m}\left(\mathrm{~L}^{*} \mathrm{~W} * \mathrm{H}\right)$. The oil filled in the container is at a level of the lower half of the tube so that it simulates the heating of the absorber tube from the lower half only. In this way, a non-uniform heat distribution can be created and controlled. A dual function tank is connected to the exit of the heating coil. It can be used as a heat exchanger and as a storage tank. Then a pump of $250 \mathrm{~W}$ is connected to the tank exit through an electronic flow sensor for measuring flow rate. A flow control valve is fixed after the pump to manually control the flow rate.

Number of thermocouples are fixed as follows:

- Twelve thermocouples of $1 \mathrm{~mm}$ diameter are inserted around the tube at an angel of $30^{\circ}$ around the circumference for circumferential inside-wall temperature measurement.

- Two thermocouples at the inlet and at the outlet for measuring the average inlet and outlet temperature of the absorber tube.

- Two thermocouples are fixed at the inlet and exit of cooling water to the tank with heat exchanger.

- Two thermocouples are fixed at the inlet and exit of the heat exchanger.

- Three thermocouples are fixed inside the tank for measuring its temperature.

Figure 3 illustrates the test rig with all components.

\section{MEASURING TECHNIQUE}

To measure all the above parameters simultaneously, an implemented technique in designed, manufactured and calibrated before the measurements.

- $\quad$ Figure 4 shows the block diagram of the measurement \& data logger system. As shown, the system is designed to acquire the data from:

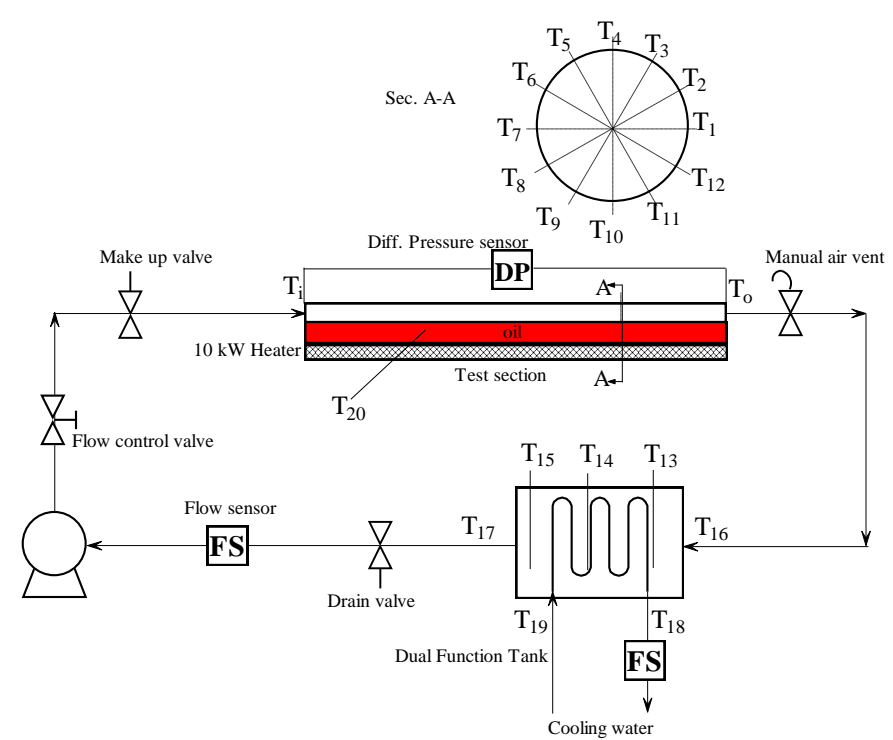

Fig. 2 Layout of the test facility

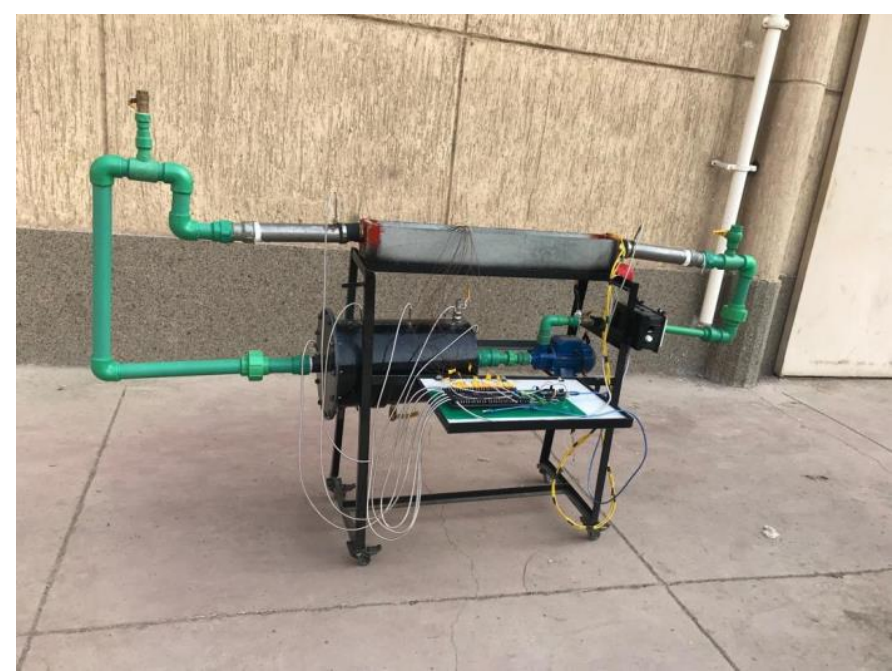

Fig. 3 Test Facility

- 32 Temperature Sensor (K-Type Thermocouples, higher than the actual number of thermocouples).

- Flow meter.

- Differential Pressure Sensor.

- The system stores the data instantaneously of the measured variables directly on a computer Excel sheet using Visual Basic and Macros Programming.

The System can be divided into three parts:

- Sensors and Signal Conditioning circuits.

- Controller.

- Data logger system.

\section{- Sensors and Signal Conditioning circuits}

As shown from Fig. 4, the system consists of 3 types of sensors:

- Temperature Sensors: 
The Temperature measurement subsystem must acquire data from more than $25 \mathrm{~K}$-Type thermocouples distributed over the Mechanical system, which in turn requires a multiplexing technique to switch between the distributed thermocouples.

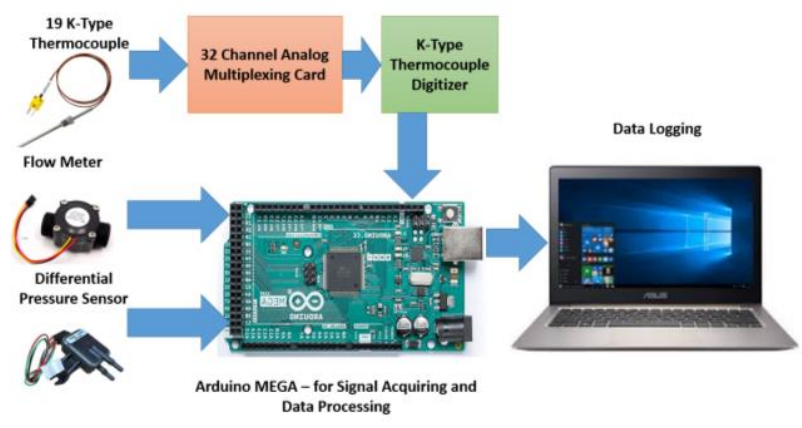

Fig. 4 System Block Diagram

$32 * 2$ Channels Analog Multiplexer was designed for this purpose, the multiplexer was simulated using Proteus software package and implemented as double side PCB at the Egyptian NTI. Fig. 5 shows the multiplexer design while Figure 6 shows the PCB design, finally Figure 7 shows the final implementation.

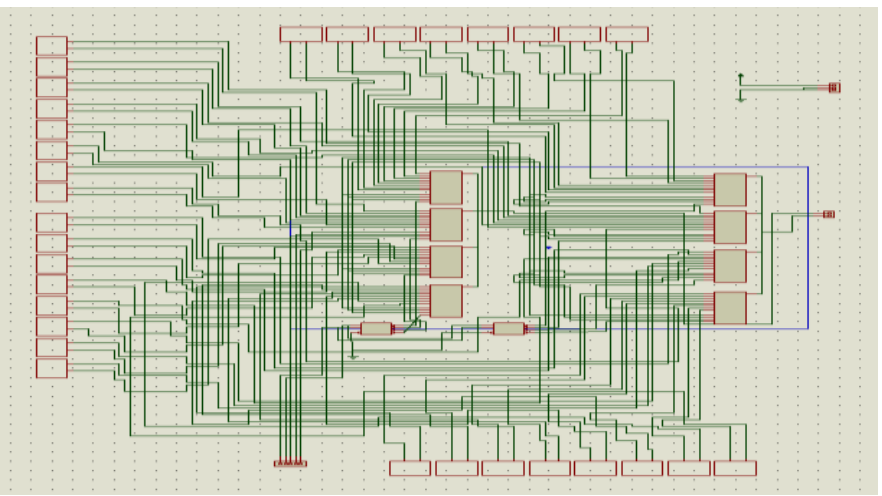

Fig. 5 Multiplexer design

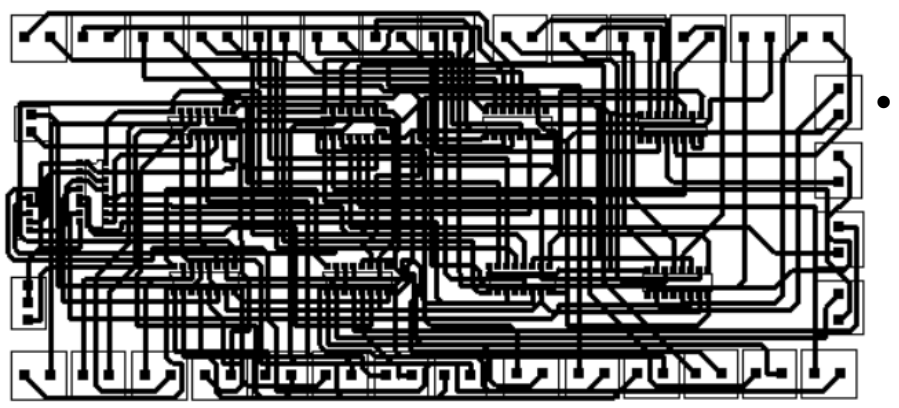

Fig. 6 MUX PCB Design

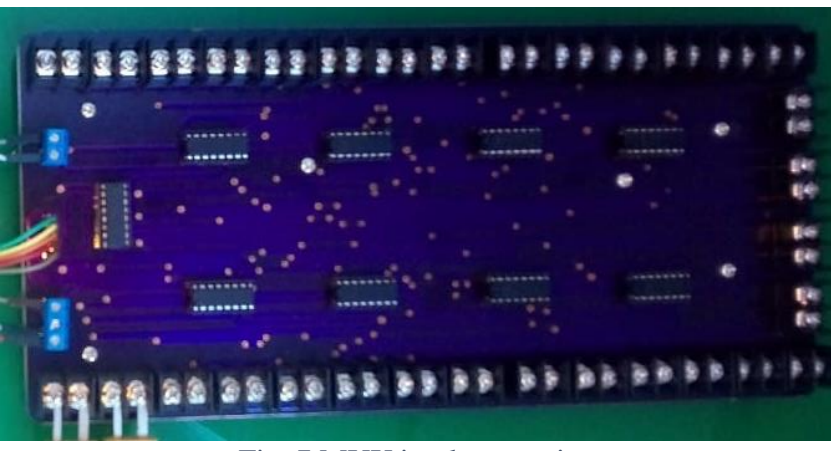

Fig. 7 MUX implementation

The MUX design based on the low resistance Analog/Digital multiplexer chip (4051) The CD4051B is a single 8-Channel multiplexer having three binary control inputs, A, B, and $\mathrm{C}$, and an inhibit input. The three binary signals select 1 of 8 channels to be turned on, and connect one of the 8 inputs to the output.

In order to convert the K-Type Thermocouple signal into an acceptable digital values the MAX 6675 Chip is used (as shown in Fig. 8). The MAX6675 performs cold-junction compensation and digitizes the signal from a Type-K thermocouple. The data is output in a 12-bit resolution, SPITM compatible,

read-only format. This converter resolves temperatures to $0.25^{\circ} \mathrm{C}$, allows readings as high as $+1024^{\circ} \mathrm{C}$, and exhibits thermocouple accuracy of $8 \mathrm{LSBs}$ for temperatures ranging from $0^{\circ} \mathrm{C}$ to $+700^{\circ} \mathrm{C}$

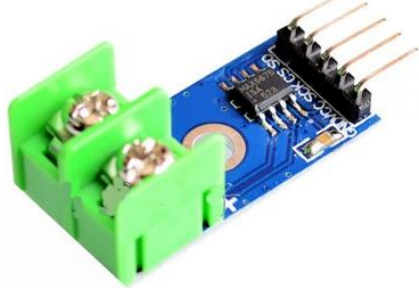

Fig. 8 MAX6675 K-Thermocouple Digitizer

- Flow Sensor:

Flow sensor (Fig. 9) consists of a plastic valve body, a water rotor, and a hall-effect sensor. When water flows through the rotor, rotor rolls. Its speed changes with different rate of flow. The hall-effect sensor outputs the corresponding pulse Signal

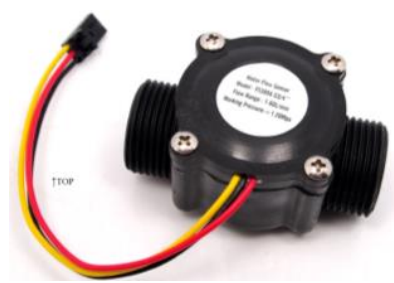

Fig. 9 Flow Sensor 
International Journal of Applied Energy Systems, Vol. 2, No. 2, July 2020 ISSN: 2636 - 3712 (Printed Version) ISSN: 2636 - 3720 (Online Version) Special Issue: ICEE-2019

Table 1 shows the technical specifications of the flow sensor. The sensor output is a TTL level and directly connected to the controller without further signal conditioning circuits.

Table 1: Technical Specs. of the flow sensors

\begin{tabular}{|c|c|}
\hline Mini. Wokring Voltage & DC $4.5 \mathrm{~V}$ \\
\hline Max. Working Current & $15 \mathrm{~mA}(\mathrm{DC} 5 \mathrm{~V})$ \\
\hline Working Voltage & $5 \mathrm{~V} \sim 24 \mathrm{~V}$ \\
\hline Flow Rate Range & $1 \sim 60 \mathrm{~L}$ min \\
\hline Load Capacity & $\leq 10 \mathrm{~mA}(\mathrm{DC} 5 \mathrm{~V})$ \\
\hline Operating Temperature & $\leq 80^{\circ} \mathrm{C}$ \\
\hline Liquid Temperature & $\leq 120^{\circ} \mathrm{C}$ \\
\hline Operating Humidity & $35 \% \sim 90^{\circ} \% \mathrm{RH}$ \\
\hline Water Pressure & $\leq 2.0 \mathrm{MPa}$ \\
\hline Storage Temperature & $-25{ }^{\circ} \mathrm{C} \sim+80^{\circ} \mathrm{C}$ \\
\hline Storage Humidity & $25^{\circ} \sim 95^{\circ} \% \mathrm{RH}$ \\
\hline
\end{tabular}

- Differential Pressure Sensor:

MPXV7002 Integrated Silicon Pressure Sensor (Fig. 10) is used. The MPXV7002 is on chip signal conditioned, Temperature Compensated and Calibrated The MPXV7002 series piezo resistive transducers are state-of-the-art monolithic silicon pressure sensors designed for a wide range of applications, but particularly those employing a microcontroller or microprocessor with A/D inputs. This transducer combines advanced micromachining techniques, thin film metallization, and bipolar processing to provide an accurate, high level analog output signal that is proportional to the applied pressure.

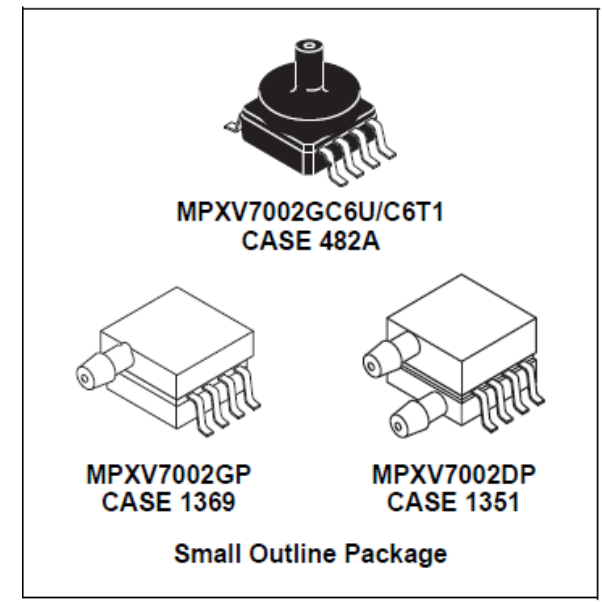

Fig. 10 Pressure Sensor

\section{Controller:}

The required controller must be capable of:

- Interfacing SPI communication (for MAX6675).

- Interfacing the Digital IO TTL for flow meter sensor, with internal counter.

- Interfacing Analog Signals (has a A/D converter).

- Fast Operation $10 \mathrm{MHz}$ or Higher.

All the required capabilities are available in the ArduinoMEGA shown in the Fig. 11.

The Arduino Mega 2560 is a microcontroller board based on the ATmega2560. It has 54 digital input/output pins (of which 15 can be used as PWM outputs), 16 analog inputs, 4 UARTs (hardware serial ports), a $16 \mathrm{MHz}$ crystal oscillator, a USB connection, a power jack, an ICSP header, and a reset button. It contains everything needed to support the microcontroller; simply connect it to a computer with a USB cable or power it with an AC-to-DC adapter or battery to get started.

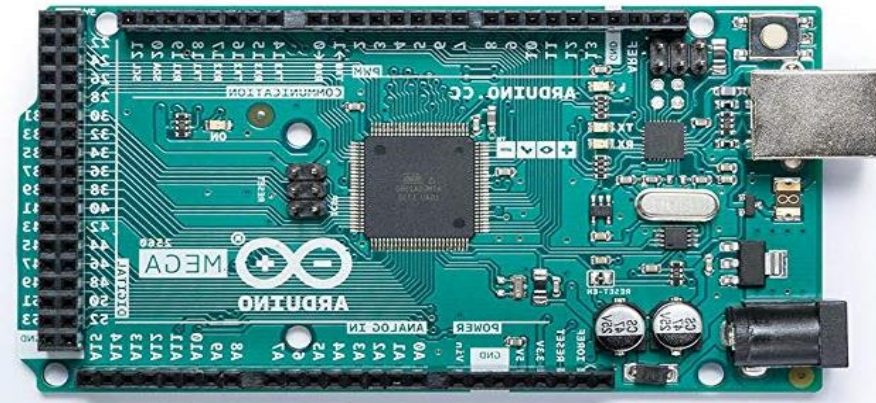

Fig. 11 Arduino MEGA

Figure 12 shows the complete system

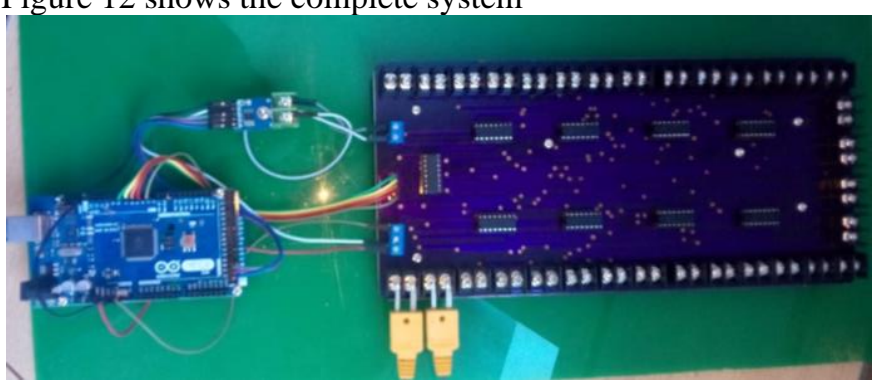

Fig. 12 Measuring System

\section{RESULTS AND DISCUSSION}

Before the installation of the measuring system, calibration procedures gave been carried out. Fig. 13 shows the calibration curve for twelve temperature sensors with the reference temperature. The is estimated for all sensors to be less than 1 percent.

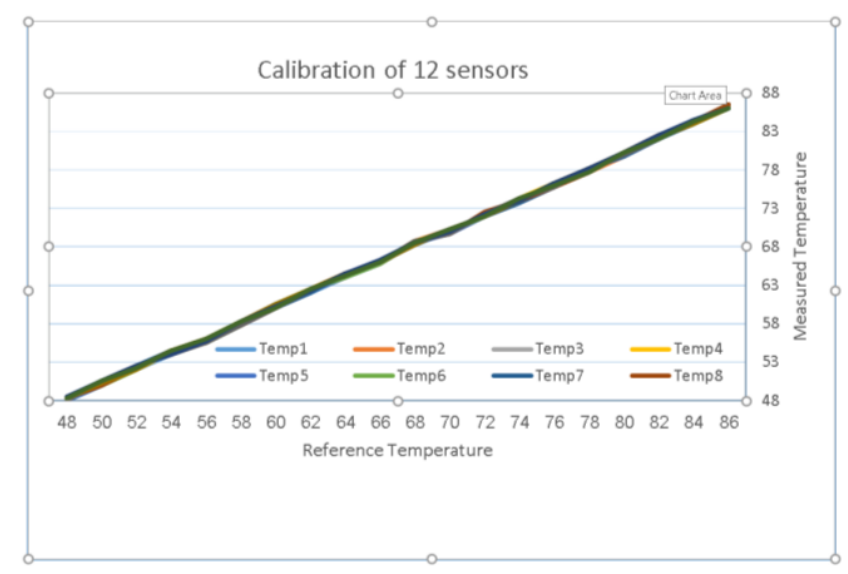

Fig. 13 Temperature sensor calibration curve 
Figure 13 shows the preliminary result of the non-uniform temperature distribution around the tube when heating the coil $2 \mathrm{~kW}$ and at flow rate of $20 \mathrm{1} / \mathrm{min}$. At this conditions, the temperature reaches $38^{\circ} \mathrm{C}$ at the top of the tube and $43^{\circ} \mathrm{C}$ at its bottom.

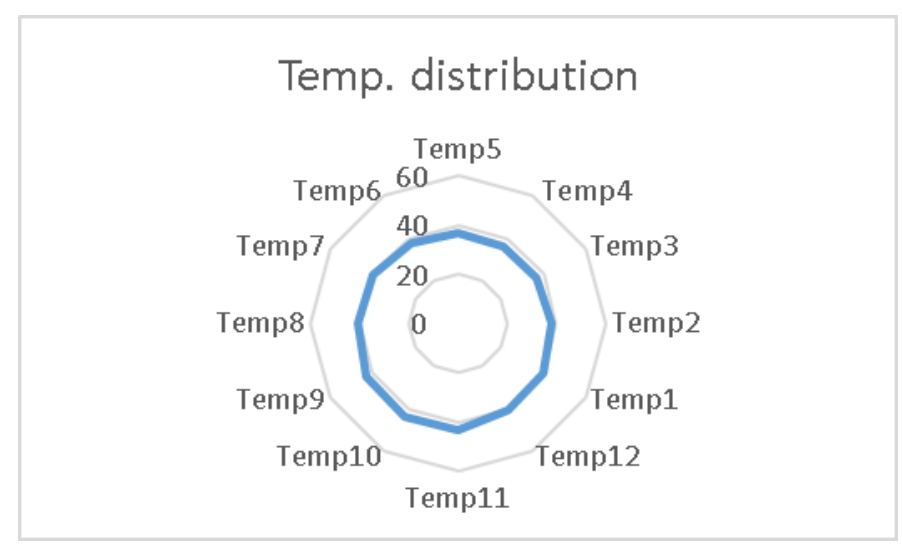

Fig. 14 Temperature around the tube

\section{CONCLUSION}

In this paper, a new implemented measuring method to measure the instantaneous temperature variation of the wall temperature of a horizontal tube used for the parabolic trough collector. The system is calibrated with an error of less than 1 percent. A sample of the non-uniform temperature distribution is obtained.

\section{ACKNOWLEDGMENT}

This work is part of a joint project funded by the Science and Technology Development Fund (STDF, Project ID 30679) of Egypt and UK department of for Business, Energy and Industrial Strategy (BEIS) and managed by the British Council UK under the grant agreement no. 332271136

\section{REFERENCES}

[1] Jeter SM. Calculation of the concentrated flux density distribution in PTCs by a semifinite formulation. Sol Energy 1986;37:335-45.

[2] Dudley, V.E., Kolb, G.J, 1994. Test Results: SEGS LS-2 Solar Collector. SAND94-1884, p. 1-12.

[3] ODEH, S., MORRISON, G., \& BEHNIA, M. (1998). Modelling of parabolic trough direct steam generation solar collectors. Solar Energy. 62, 395-406.

[4] CHENG Z.-D., HE Y.-L., WANG K., DU B.-C., \& CUI F.Q. (2014). A detailed parameter study on the comprehensive characteristics and performance of a parabolic trough solar collector system. Applied Thermal Engineering. 63, 278-289.

[5] HACHICHA, A. A., RODRIGUEZ, I., CAPDEVILA, R., \& OLIVA, A. (2013). Heat transfer analysis and numerical simulation of a parabolic trough solar collector. Applied Energy. 111, 581-592.
[6] SOKHANSEFAT, T., KASAEIAN, A., \& KOWSARY, F. (2015). Heat transfer enhancement in PTC tube using A12O3/synthetic oil nanofluid. Renewable and Sustainable Energy Reviews. 33, 636-644.

[7]KALOUDIS, E., PAPANICOLAOU, E., \& BELESSIOTIS, V. (2016). Numerical simulations of a parabolic trough solar collector with nanofluid using a twophase model. Renewable Energy. 97, 218-229.

WANG, Y., LIU, Q., SUN, J., LEI, J., JU, Y., \& JIN, H. (2017). A new solar receiver/reactor structure for hydrogen production. Energy Conversion and Management. 133, 118126.

[8] BARLEV D., STROEVE P., \& VIDU R. (2011). Innovation in concentrated solar power. Solar Energy Materials and Solar Cells. 95, 2703-2725.

[9] WWW. dlr.de.com) 12

[10] NAHHAS, T., PY, ., G E GOIRE, S., CRISTOFARI, C., PHAM MINH, D., BESSADA, C., OLIVES, . (201 ).

Materials and thermal storage systems y sensi le heat for thermodynamic electro-solar plants. The se de doctorat Energe tique et Ge nie des Proce de s : Perpignan : 2017. 